Leemans, K., Deliens, L., Block, L. van den, Stichele, R. Vander, Francke, A.L., Cohen, J. Systematic quality monitoring for specialized palliative care services: development of a minimal set of wuality indicators for palliative care study (QPAC). American Journal of Hospice \&

Palliative Medicine: 2017, 34(6), 532-546

\begin{tabular}{l|l}
$\begin{array}{l}\text { Postprint } \\
\text { Version }\end{array}$ & 1.0 \\
\hline Journal website & $\underline{\text { http://ajh.sagepub.com/content/early/2016/04/07/1049909116642174.long }}$ \\
\hline Pubmed link & $\underline{\text { http://www.ncbi.nlm.nih.gov/pubmed/27059060 }}$ \\
DOI & $10.1177 / 1049909116642174$
\end{tabular}

This is a NIVEL certified Post Print, more info at http://www.nivel.eu

\title{
Systematic Quality Monitoring For Specialized Palliative Care Services: Development of a Minimal Set of Quality Indicators for Palliative Care Study (QPAC)
}

\author{
Kathleen Leemans, $P^{1,2}{ }^{1,2}$ L. Deliens, PhD ${ }^{1,2,3}$ L. VAN DEN BLOCK, PhD ${ }^{1,2,4}$ R. VANDER \\ STICHELE, PHD ${ }^{5}$ A. L. FrANCKE, PHD $^{6,7}$ J. COHEN, PHD ${ }^{1,2}$ \\ ${ }^{1}$ End-of-Life Care Research Group, Vrije Universiteit Brussel (VUB), Brussels, Belgium \\ ${ }^{2}$ Ghent University, Ghent, Belgium \\ ${ }^{3}$ Department of Medical Oncology, Ghent University, Ghent, Belgium \\ ${ }^{4}$ Department of General Practice, Vrije Universiteit Brussel (VUB), Brussels, Belgium \\ ${ }^{5}$ Department of Pharmacology, Ghent University, Ghent, Belgium \\ ${ }^{6}$ Department of Public and Occupational Health, VU University Medical Center, EMGO \\ Institute for Health and Care Research, Amsterdam, the Netherlands \\ ${ }^{7}$ NIVEL-Netherlands Institute for Health Services Research, Utrecht, the Netherlands.
}

\begin{abstract}
Background: A feasibility evaluation of a comprehensive quality indicator set for palliative care identified the need for a minimal selection of these indicators to monitor quality of palliative care services with short questionnaires for the patients, caregivers, and family carers.

Objectives: To develop a minimal indicator set for efficient quality assessment in palliative care.

Design: A 2 round modified Research ANd Development corporation in collaboration with the University of California at Los Angeles (RAND/UCLA) expert consultation.

Setting/Patients: Thirteen experts in palliative care (professionals and patient representatives).

Measurements: In a home assignment, experts were asked to score 80 developed indicators for "priority" to be included in the minimal set on a scale from 0 (lowest priority) to 9 (highest priority). The second round consisted of a plenary meeting in which the minimal set was finalized.

Results: Thirty-nine of the 80 indicators were discarded, while 19 were definitely selected after the home assignment, and 22 were proposed for discussion during the meeting; 12 of these survived the selection round. The final minimal indicator set for palliative care consists of 5 indicators about the
\end{abstract}


Leemans, K., Deliens, L., Block, L. van den, Stichele, R. Vander, Francke, A.L., Cohen, J. Systematic quality monitoring for specialized palliative care services: development of a minimal set of wuality indicators for palliative care study (QPAC). American Journal of Hospice \& Palliative Medicine: 2017, 34(6), 532-546

physical aspects of care; 6 about the psychosocial aspects of care; 13 about information, communication, and care planning; 5 about type of care; and 2 about continuity of care.

Conclusion: A minimal set of 31 indicators reflecting all the important issues in palliative care was created for palliative care services to assess the quality of their care in a quick and efficient manner. Additional topic-specific optional modules are available for more thorough assessment of specific aspects of care.

\section{INTRODUCTION}

With a growing culture of quality assessment in palliative care (PC), one of the greatest challenges for specialized PC services is to evaluate their care systematically and continuously in order to improve it at the level of patients and their families. ${ }^{1 \Downarrow \Downarrow \Downarrow-~}$ ${ }^{5}$ Quality indicators, that is, measurable aspects of care addressing a specific aspect of care, can be a helpful tool in achieving improvement and transparency at aggregated service level. ${ }^{6,7}$ A number of internal quality indicators of palliative or end-of-life care have been developed. ${ }^{8,9}$ However, these often focus only on patients with cancer or on specific dimensions for PC such as physical aspects of care. ${ }^{10.18}$ The Council of Europe has stated a need for quality indicators for PC that assess all relevant dimensions and hence reflect the multidisciplinary character of PC. ${ }^{3}$ In Belgium in 2009, we therefore started to develop a valid comprehensive quality indicator set and accompanying measurement procedure for $\mathrm{PC}^{19}$ to allow specialized PC services to evaluate the quality of their care delivery. In Belgium, these services include multidisciplinary palliative home care teams, PC units, and multidisciplinary palliative support teams in hospitals. We followed a scientifically rigorous method combining evidence and consensus (Figure 1) as suggested by Campbell et al for the development of quality indicators, ${ }^{20}$ including:

1. Systematic literature review to identify existing indicators for $\mathrm{PC}{ }^{8}$

2. Identification of the important domains of PC (see Table 1) and the priority themes and indicators of quality of PC using a robust consensus methodology taking into account perspectives of relevant stakeholders, that is, patients, family carers, professional caregivers, and policy makers. ${ }^{21}$ This resulted in an extensive comprehensive set of structure, process, and outcome quality indicators for PC, partly composed of existing (validated) international indicators and partly of newly developed indicators (for the domains and themes that were not covered by existing indicators, following a Research ANd Development corporation in collaboration with the University of California at Los Angeles (RAND/UCLA) consensus method involving literature review and 2 expert panel rounds (this development process is described elsewhere ${ }^{21,22}$ ).

3. Operationalization of the selected quality indicators into measurement instruments and methods. Five different questionnaires were developed ${ }^{21}:$ (1) for living patients (or a proxy) receiving care from a specialized PC service, (2) for the most involved professional caregiver of these patients (nurse, physician, or psychologist of the team), (3) for bereaved family members of patients who died under care of a specialized PC service, (4) for the most involved caregiver of these patients (nurse, physician, or psychologist of the 
Leemans, K., Deliens, L., Block, L. van den, Stichele, R. Vander, Francke, A.L., Cohen, J. Systematic quality monitoring for specialized palliative care services: development of a minimal set of wuality indicators for palliative care study (QPAC). American Journal of Hospice \& Palliative Medicine: 2017, 34(6), 532-546

team), and (5) for the coordinator of the team (one-time only questionnaire for 4 structure indicators).

4. A feasibility study of the quality indicators and measurement procedure in 9 PC services in Belgium. This phase indicated good feasibility, usefulness, face validity, and discriminative power. ${ }^{22}$ Still the caregivers indicated that some changes in the measurement procedure were required and a desire to have fewer core indicators making the measurement and evaluation more feasible and better allowing them to focus on core working points for their team. The challenges for a final set, to be used in PC practice, was to be limited in terms of work-load, overload of information, and length of the questionnaires and to be feasibly measured and evaluated by the PC services themselves.

[FIGURE 1.] [TABLE 1. ]

The aim of the current study was to provide PC services with a minimal core set of quality indicators for PC services and an accompanying measurement procedure for fast, efficient, and repeated comprehensive monitoring of the quality of their care delivery.

\section{METHODS}

\section{Design}

In order to select a core minimal quality indicator set, a 2-round modified RAND/UCLA panel was conducted. This method combines scientific evidence with consensus among experts in the field. ${ }^{23}$ Experts were asked to select a core set of quality indicators among the extensive set of indicators that were previously identified. In a first phase, the experts were assigned a home assignment to preliminarily score the indicators on priority (in this case to be part of a minimal set for PC); then a plenary discussion took place to reach consensus on the final selection of indicators.

\section{Participants}

The panel was composed of experts in the field of PC in Belgium. They were recruited from 3 areas: PC researchers, PC providers, and PC users. We balanced the number of experts per area according to the importance of that area. In total 13 experts participated: 1 researcher, 4 physicians, 4 nurses, 2 psychologists, 1 volunteer, and 1 representative of a patient organization.

\section{Rating Process}

During the development phase, the indicator set had been operationalized into 4 types of questionnaires ( 1 for the patient, most involved caregiver, family carer, and family physician). We predetermined that a maximum of 8 indicators should be measured per questionnaire for the minimal set. In this way, all relevant perspectives would be covered and the length of each questionnaire would correspond to 1 page, which had been identified by the caregivers as ideal. Hence, of the list of 80 previously developed and validated process and outcome indicators, a maximum of 32 (8 per respondent type) could be selected.

One month before the meeting, the panel members received this list of indicators, with descriptions of each indicator's numerator, denominator, and measurement 
Leemans, K., Deliens, L., Block, L. van den, Stichele, R. Vander, Francke, A.L., Cohen, J. Systematic quality monitoring for specialized palliative care services: development of a minimal set of wuality indicators for palliative care study (QPAC). American Journal of Hospice \& Palliative Medicine: 2017, 34(6), 532-546

question(s) accompanied by a clear assignment and a document explaining the background and rationale for each indicator and results of the measurement in the feasibility study for each indicator. The experts were asked to score each indicator for priority to be included in the minimal indicator set on a scale from 1 to 9 , with 1 equaling "lowest priority" and 9 equaling "highest priority." Furthermore, they were asked to choose the 8 indicators with highest priority per questionnaire respondent type.

\section{Analysis}

After receiving all score sheets, the researcher calculated for each indicator the median score and the number of times the experts marked it with "highest priority." The RAND/UCLA method prescribes that indicators with a median score of 7, 8, or 9 on which consensus was reached (ie, no more than 2 experts scored the indicator with a 1,2 , or 3 ) are retained immediately; indicators with a median score of 1,2 , or 3 on which consensus was reached (ie, no more than 2 experts scored the indicator 7 , 8 , or 9) are discarded immediately; all other indicators, that is, those on which consensus was not reached and those with a median score of 4, 5, and 6, are discussed with all experts during the meeting in order to reach consensus on the final selection. Following this method, 67 of the 80 indicators would have been retained immediately, exceeding the target number of 32 . We therefore applied a stricter selection method: only the indicators with a median score of 7,8 , or 9 on which consensus was reached and marked by 7 or more panel members with highest priority were immediately selected for the minimal set. Indicators with a median score of 6 or less were definitely discarded. All other indicators scoring high $(7,8$, or 9) but on which consensus was not reached or was marked by no more than 6 panel members with highest priority were discussed during the meeting.

\section{Plenary Discussion Meeting}

During a 1-day discussion meeting, the selection method and results of the home assignment were presented to the experts: which indicators per questionnaire respondent type were already selected for the minimal set and which still needed to be discussed and decided on. In order to preserve the coverage of all aspects inherent to PC, we informed the panel members which domains were yet underrepresented; they could take this into account though they were not obliged to select the indicators to complete the domains.

\section{Measurement Procedure}

The measurement procedure follows a snapshot approach: A cross-sectional inclusion method is used which requires the PC services to list 2 groups of patients on 1 given day (ie, the day of the assessment): all patients who are enrolled in the PC service are still alive on that specific day and all patients who were enrolled in the service have died in a given period. For the first group, a questionnaire is provided to the patient and the most important professional caregiver at that point in time and for the second group to the most important family carer and the most involved professional caregiver. We revised the procedure based on the results of the interviews that were part of the feasibility study. ${ }^{22}$ During these interviews with the caregivers who worked with the indicators, we analyzed the different steps in the measurement procedure: selection of the different respondents, sending out the questionnaires, and feedback of the indicator scores to the teams. 
Leemans, K., Deliens, L., Block, L. van den, Stichele, R. Vander, Francke, A.L., Cohen, J. Systematic quality monitoring for specialized palliative care services: development of a minimal set of wuality indicators for palliative care study (QPAC). American Journal of Hospice \& Palliative Medicine: 2017, 34(6), 532-546

\section{Ethical Concerns}

In the recruitment letter for the experts, the confidentiality and anonymity of the research findings were guaranteed. As no personal information was collected from the experts, no informed consent was requested. The current study is part of a larger feasibility project for which the protocol was approved by the Ethical Review Board of Brussels University Hospital of the Vrije Universiteit Brussel (143201112708).

\section{RESULTS}

In total, 13 experts participated in the expert consultation. All experts completed the home assignment; 11 of them were present at the plenary discussion meeting. Based on the first scoring round of the home assignment, 39 indicators were discarded immediately (consensus over low priority), 19 were selected immediately (consensus over highest priority), and 22 had to be discussed (no consensus). Of those, 13 could still be selected (in order not to exceed the targeted maximum of 32 indicators). At the end of the discussion, the minimal set for home and hospital PC in Belgium consisted of 31 process and outcome indicators: 5 about physical aspects of care; 3 about the psychosocial spiritual aspects; 11 about information, communication, and care planning; 5 about type of care; 3 about continuity of care; and 4 about care for family. Hence the minimal set covers all the original quality domains. An elaborated presentation of the minimal set including numerator, denominator, question, domain, and source can be found in Table 2 . The other 49 process and outcome indicators were divided into 3 optional thematic modules: (1) biopsychosocial spiritual aspects, (2) communication and care planning, and (3) coordination of care. Finally, the 4 structure indicators (not involved in this study) were retained to be measured alongside the minimal set.

\section{[TABLE 2. ]}

\section{Quality Indicators Per Respondent Type}

\section{Patients}

Only 3 indicators were selected immediately so 5 of 6 needed to be selected during the discussion (Table 3). Because of the overlap between indicator number 7 "Percentage of patients who indicated that the professional caregivers were most of the time or always attentive to their personal situation and needs" and number 8 "Percentage of patients who indicated that the professional caregivers regularly assessed how they were feeling," the experts decided to discard number 7 and include the other in the minimal set.

\section{[TABLE 3. ]}

\section{Professional caregivers}

Experts still needed to select 4 of 7 indicators during the meeting (Table 4). They decided to retain indicator number 8 "Percentage of patients who were asked how they felt about end of life decisions and euthanasia." Furthermore, they choose number 16 "Percentage of patients whose caregivers were given the care objectives and resuscitation status during or after admission or starting PC," 1 of the 3 
Leemans, K., Deliens, L., Block, L. van den, Stichele, R. Vander, Francke, A.L., Cohen, J. Systematic quality monitoring for specialized palliative care services: development of a minimal set of wuality indicators for palliative care study (QPAC). American Journal of Hospice \& Palliative Medicine: 2017, 34(6), 532-546

indicators on transfers. Finally, they selected indicators number 9 and 10 on communication and care planning.

\section{[TABLE 4. ]}

\section{Family carers}

Five indicators were selected and 7 still needed to be discussed after the home assignment (Table 5). The experts selected indicator number 19 on quality of death and number 21 on after care. The last indicator number 23 "Percentage of family carers who were given as much assistance as necessary with the care process" was retained, as it was seen as covering a wide range of aspects.

\section{[TABLE 5.]}

Scores and Decision Per Round of the Indicators Included in the Questionnaire for Family Carers. $^{a}$

\section{Physicians (for the after-death questionnaire)}

As the physicians' questionnaire originally included only 9 indicators, experts were not asked to prioritize the 8 most important in this list. Based on the median scores only, 7 indicators were selected for the minimal set. The experts decided not to add any more to the minimal set, as there was no agreement on the validity of the remaining 2 indicators (Table 6).

\section{[TABLE 6. ]}

\section{Measurement procedure}

Based on the conclusions drawn from the feasibility study, 3 major changes were made to the measurement procedure: For measurement of quality indicators after death (family carer and physician questionnaire), the period of inclusion was changed from between 6 weeks and 6 months after death to between 4 weeks and 4 months after death; PC teams will collect the completed questionnaires themselves (instead of the research team) and deliver them afterward to the researchers for processing purposes. Three more steps were added to the procedure in order to embed the quality measurements into a continuous quality assessment trajectory: interpretation of results by the team, taking action to improve quality of care, and planning of the next measurement period (approximately 6 month later). This resulted in an optimized 6-step procedure ${ }^{19}$ : Services appoint a coordinator (step 1) who makes the selection of all respondents (step 2). Anonymized responses are processed by an independent research team that calculates the quality indicator scores and feeds them back to the service in the form of a report (step 3). The care team members should then plan to meet to interpret the scores, distil working points, and set up an action plan to improve quality of care (step 4 and 5). In principle, services need to repeat the measurement and evaluation procedure every 6 months (step 6). 
Leemans, K., Deliens, L., Block, L. van den, Stichele, R. Vander, Francke, A.L., Cohen, J. Systematic quality monitoring for specialized palliative care services: development of a minimal set of wuality indicators for palliative care study (QPAC). American Journal of Hospice \& Palliative Medicine: 2017, 34(6), 532-546

\section{DISCUSSION}

Using a modified RAND/UCLA method, our study identified an operational minimal quality indicator set for PC services covering all aspects inherent to PC and an accompanying measurement procedure. As such we are able to present a comprehensive quality indicator set suitable for quick and efficient assessment of quality of care provided by palliative home care teams, PC units, and palliative support teams in hospitals.

We started from a comprehensive indicator set that was identified and tested following rigorous scientific methods. ${ }^{21,22}$ The RAND method used to select the minimal indicator set and consisting of a homework assignment and a panel discussion is the most appropriate design to determine the extent of agreement among experts on a specific issue and is particularly useful in developing and identifying quality indicator sets. ${ }^{35}$ The panel consisted of caregivers from different disciplines (ie, physicians, psychologists, and nurses from home and hospital settings) together with 2 experts representing the perspective of patients and their families. ${ }^{36}$ However, some limitations of the study have to be acknowledged. Two experts who participated in the home assignment were not able to attend the expert meeting as a result of their uncertain working schedules. An analysis of their scoring results indicates that their absence likely would not have influenced the ultimate result as their scores in the homework assignment were similar to those of other panel members. Additionally, most panel members scored all indicators high for priority. As we anticipated this problem, we also asked the individual experts to pick the 8 most important indicators in order to differentiate more between the indicators. A possible solution for the high scoring propensity can be to define every point on the scale very precisely and to provide examples of how to score the indicators for priority.

At this time, all PC services in Flanders, Belgium, are invited to work voluntarily with the minimal quality indicator set and optional thematic modules in order to monitor their practice. By avoiding obligatory use of the indicators, caregivers will be highly motivated to perform the quality measurement systematically and will be more likely to apply the quality information in a well-considered manner. Palliative care teams should never be expected to reach certain levels of indicator scores. This might lead to unnecessary changes in care processes and lack of consideration for what is best for the patient and the family. The quality indicator set in its present form is designed for the internal monitoring of PC services. Still, measuring quality does not necessarily improve it. Therefore, the quality indicators need to be embedded into an improvement trajectory for which the current measurement procedure provides a good basis. Furthermore, the quality indicators may provide a useful tool for hospitals which want to measure quality of PC systematically and hence to be in line with the current requirements of accreditation programs. When implementing the minimal indicator set at wider scale, the usefulness and feasibility would need to be further evaluated and validated before it can be used as a tool to evaluate improvement programmes. ${ }^{37}$ Therefore, the implementation study may provide useful information on the validity of the indicators and accompanying questions: When deemed necessary in the evaluation indicators as well as questionnaires need to be adapted based on other more recently developed and validated instruments that were developed to monitor the quality of PC. . $^{13,38,39}$ 
Leemans, K., Deliens, L., Block, L. van den, Stichele, R. Vander, Francke, A.L., Cohen, J. Systematic quality monitoring for specialized palliative care services: development of a minimal set of wuality indicators for palliative care study (QPAC). American Journal of Hospice \& Palliative Medicine: 2017, 34(6), 532-546

\section{CONCLUSION}

In identifying and operationalizing a minimal set of quality indicators and accompanying measurement procedure, we have provided PC services with an indicator tool for quick and efficient assessment of the quality of the care they deliver in Belgium. Systematic measurement (every 6 months) with these indicators can generally identify the aspects of care that are going well and those that need improvement, hence serving as a barometer for the PC delivered by the specific service. Depending on the priorities different PC services set, action can be taken by the team to improve their care. Further evaluation of the usefulness and feasibility of the minimal indicator set is warranted once it has been implemented on a wider scale.

\section{Acknowledgments}

We thank all the panel members for their time and cooperation in the study. We thank Jane Ruthven for her help in language editing. This study is part of the "Flanders Study to Improve End-of-Life Care and Evaluation Tools (FLIECEproject)," a collaboration between the Vrije Universiteit Brussel, Ghent University, the Katholieke Universiteit Leuven, Belgium, and VU University Medical Centre Amsterdam, the Netherlands. Joachim Cohen and Lieve Van den Block are postdoctoral fellows of the Research Foundation Flanders.

\section{Article Notes}

- Declaration of Conflicting Interests The author(s) declared no potential conflicts of interest with respect to the research, authorship, and/or publication of this article.

- Funding The author(s) disclosed receipt of the following financial support for the research, authorship, and/or publication of this article: This study is supported by a grant from the Flemish government agency for Innovation by Science and Technology (agentschap voor Innovatie door Wetenschap en Technologie) (SBO IWT nr. 100036), and by the Flemish League against Cancer.

\section{REFERENCES}

Aoun SM, Nekolaichuk C . Improving the evidence base in palliative care to inform practice and policy: thinking outside the box. J Pain Symptom Manage. 2014;48(6):1222-1235.

Aziz NM, Miller JL, Curtis JR . Palliative and end-of-life care research: embracing new opportunities. Nurs Outlook. 2012;60(6):384-390.

Parliamentary Assembly of the Council of Europe. Resolution 1649 (2009): Palliative care: a model for innovative health and social policies. In: Directorate General I - Human Rights Directorate. Strasbourg: Texts of the Council of Europe on bioethical matters, Volume II. Council of Europe; 2014:68-70.

Dy SM, Lupu D, Seow H. Progress towards systems of quality measurement that capture the essence of good palliative care. Palliat Med. 2012;26(4):291-293.

Evans CJ, Harding R, Higginson IJ. 'Best practice' in developing and evaluating palliative and end-of-life care services: a meta-synthesis of research methods for the MORECare project. Palliat Med. 2013;27(10):885-898.

Ostgathe C, Voltz R . Quality indicators in end-of-life care. Curr Opin Support Palliat Care. 2010;4(3):170-173.

Strengthening of palliative care as a component of integrated treatment within the continuum of care, World Health Organization, 2014. 
Leemans, K., Deliens, L., Block, L. van den, Stichele, R. Vander, Francke, A.L., Cohen, J. Systematic quality monitoring for specialized palliative care services: development of a minimal set of wuality indicators for palliative care study (QPAC). American Journal of Hospice \& Palliative Medicine: 2017, 34(6), 532-546

De Roo ML, Leemans K, Claessen SJ, et al . Quality indicators for palliative care: update of a systematic review. J Pain Symptom Manage. 2013;46(4):556-572.

Pasman HR, Brandt HE, Deliens L, Francke AL. Quality indicators for palliative care: a systematic review. J Pain Symptom Manage. 2009;38(1):145-156.

Claessen SJ, Francke AL, Belarbi HE, Pasman HR, van der Putten MJ, Deliens L. A new set of quality indicators for palliative care: process and results of the development trajectory. J Pain Symptom Manage. 2011;42(2):169-182.

deVos M, Graafmans W, Keesman E, Westert G, van der Voort PH . Quality measurement at intensive care units: which indicators should we use? J Crit Care. 2007;22(4):267-274.

Eagar K, Watters P, Currow DC, Aoun SM, Yates P. The Australian Palliative Care Outcomes Collaboration (PCOC)-measuring the quality and outcomes of palliative care on a routine basis. Aust Health Rev. 2010;34(2):186-192.

Kamal AH, Gradison M, Maguire JM, Taylor D, Abernethy AP . Quality measures for palliative care in patients with cancer: a systematic review. J Oncol Pract. 2014;10(4):281287.

Lundstrom S, Axelsson B, Heedman PA, Fransson G, Furst CJ . Developing a national quality register in end-of-life care: The Swedish experience. Palliat Med. 2012;26(4):313321.

Martinsson L, Furst CJ, Lundstrom S, Nathanaelsson L, Axelsson B . Registration in a quality register: a method to improve end-of-life care-a cross-sectional study. BMJ Open. 2012;2(4).

Seow H, Snyder CF, Shugarman LR, et al . Developing quality indicators for cancer endof-life care: proceedings from a national symposium. Cancer. 2009;115(17):3820-3829.

Wennekes $\mathrm{L}$. Development and validation of quality indicators for cancer care[published online October 29, 2013]. Nijmegen. 2013.

Woitha K Van BK, Ahmed N, et al . Development of a set of process and structure indicators for palliative care: the Europall project. BMC Health Serv Res. 2012;12:381.

Cohen J, Leemans $\mathrm{K}$. How can you prove that you are delivering good care? Monitoring the quality of palliative care using quality indicators. Eur J Palliat Care. 2014;21(5):228-231.

Campbell SM, Kontopantelis E, Hannon K, Burke M, Barber A, Lester HE . Framework and indicator testing protocol for developing and piloting quality indicators for the UK quality and outcomes framework. BMC Fam Pract. 2011;12:85.

Leemans K, Cohen J, Francke AL, et al . Towards a standardized method of developing quality indicators for palliative care: protocol of the Quality indicators for Palliative Care $(Q-$ PAC) study. BMC Palliat Care. 2013;12(1):6.

Leemans K, Deliens L, Francke AL, Vander SR, Van den Block L, Cohen J. Quality indicators for palliative care services: mixed-method study testing for face validity, feasibility, discriminative power and usefulness. Palliat Med. 2015;29(1):71-82.

Fitch K, Bernstein S, Aguilar M, et al . The RAND/UCLA Appropriateness Method User's Manual. Santa Monica, CA: RAND Corporation; 2001.

Peruselli C, Paci E, Franceschi P, Legori T, Mannucci F. Outcome evaluation in a home palliative care service. J Pain Symptom Manage. 1997;13(3):158-165.

Twaddle ML, Maxwell TL, Cassel JB, et al . Palliative care benchmarks from academic medical centers. J Palliat Med. 2007;10(1):86-98.

Keay TJ, Fredman L, Taler GA, Datta S, Levenson SA . Indicators of quality medical care for the terminally ill in nursing homes. J Am Geriatr Soc. 1994;42(8):853-860.

Cohen SR, Mount BM, Bruera E, Provost M, Rowe J, Tong K. Validity of the McGill Quality of Life Questionnaire in the palliative care setting: a multi-centre Canadian study demonstrating the importance of the existential domain. Palliat Med. 1997;11(1):3-20.

Claessen SJJ, Francke AL, Sixma H, et al . Op weg naar een CQ-index Palliatieve Zorg: meetinstrumentenontwikkeling. Utrecht, Netherlands: NIVEL; 2009.

Finlay E, Shreve S, Casarett D. Nationwide veterans affairs quality measure for cancer: the family assessment of treatment at end of life. J Clin Oncol. 2008;26(23):3838-3844.

Miyashita M, Nakamura A, Morita T, Bito S . Identification of quality indicators of end-of-life cancer care from medical chart review using a modified Delphi method in Japan. Am J Hosp Palliat Care. 2008;25(1):33-38. 
Leemans, K., Deliens, L., Block, L. van den, Stichele, R. Vander, Francke, A.L., Cohen, J. Systematic quality monitoring for specialized palliative care services: development of a minimal set of wuality indicators for palliative care study (QPAC). American Journal of Hospice \& Palliative Medicine: 2017, 34(6), 532-546

Earle CC, Neville BA, Landrum MB, et al . Evaluating claims-based indicators of the intensity of end-of-life cancer care. Int J Qual Health Care. 2005;17(6):505-509.

Munday D, Mahmood K, Dale J, King N . Facilitating good process in primary palliative care: does the Gold Standards Framework enable quality performance? Fam Pract. 2007;24(5):486-494.

Peruselli C, Marinari M, Brivio B, et al . Evaluating a home palliative care service: development of indicators for a continuous quality improvement program. J Palliat Care. 1997;13(3):34-42.

Addington-Hall J . VOICES (Vieuws of INformal Carers - Evaluation of Services). London, England: King's College School of Medicine and Dentistry; 1998.

Woitha K, Van BK, Ahmed N, et al . Validation of quality indicators for the organization of palliative care: A modified RAND Delphi study in seven European countries (the Europall project). Palliat Med. 2013.

Kotter T, Schaefer FA, Scherer M, Blozik E . Involving patients in quality indicator development - a systematic review. Patient Prefer Adherence. 2013;7:259-268.

Seow H, Snyder CF, Mularski RA, et al . A framework for assessing quality indicators for cancer care at the end of life. J Pain Symptom Manage. 2009;38(6):903-912.

Dy SM, Lorenz KA, O'Neill SM, et al . Cancer Quality-ASSIST supportive oncology quality indicator set: feasibility, reliability, and validity testing. Cancer. 2010;116(13):3267-3275.

Schenck AP, Rokoske FS, Durham DD, Cagle JG, Hanson LC . The PEACE Project: identification of quality measures for hospice and palliative care. J Palliat Med. 2010;13(12):1451-1459.

\section{TABLES}

\section{QI development method}

1. Systematic literature review

Which quality indicators already exist?

\section{Framework}

Which domains of PC need to be measured?

\section{RAND/UCLA expert panel}

Which indicators are appropriate for quality measurement in PC?
Level of comprehensiveness

Quality indicators for all palliative patients in all palliative care services

Structure

Process of palliative care

Outcome

Involvement of all stakeholders:

Caregivers, patient and family

perspective, administrators

Figure I. Standardized method for comprehensive quality indicator development in palliative care . 
Leemans, K., Deliens, L., Block, L. van den, Stichele, R. Vander, Francke, A.L., Cohen, J.

Table I. Overview of Representation of Domains of Quality of Care in the Comprehensive and Minimal Indicator Set.

\begin{tabular}{|c|c|c|c|}
\hline \multirow[b]{2}{*}{ Domains for quality of palliative care } & \multicolumn{3}{|c|}{$\begin{array}{l}\text { Number of } \\
\text { indicators }\end{array}$} \\
\hline & CS & RI & MS \\
\hline Physical aspects of care & II & 5 & 5 \\
\hline Psychosocial and spiritual aspects of care ${ }^{a}$ & 16 & I & 3 \\
\hline Communication and care planning with patient $\mathrm{t}^{\mathrm{a}}$ & 20 & 4 & 7 \\
\hline Communication and care planning with family & 6 & 2 & 3 \\
\hline Communication and care planning among caregivers ${ }^{a}$ & 3 & 0 & I \\
\hline Type of care and circumstances surrounding death & 6 & 2 & 5 \\
\hline Coordination and continuity of care & 9 & 3 & 3 \\
\hline Care for family ${ }^{\mathrm{a}}$ & 9 & 2 & 4 \\
\hline Total & 80 & 19 & 31 \\
\hline
\end{tabular}

Abbreviations: CS, complete set; RI, round I of the RAND/UCLA panel (home assignment); MS, minimal set; RAND/UCLA, Research ANd Development corporation in collaboration with the University of California at Los Angeles. ${ }^{a}$ This domain was underrepresented in the provisional selection of the minimal set after round I (home assignment). 
Leemans, K., Deliens, L., Block, L. van den, Stichele, R. Vander, Francke, A.L., Cohen, J. Systematic quality monitoring for specialized palliative care services: development of a minimal set of wuality indicators for palliative care study (QPAC). American Journal of Hospice \& Palliative Medicine: 2017, 34(6), 532-546

Table 3. Scores and Decision Per Round of the Indicators Included in the Questionnaire for Patients. ${ }^{2}$

\begin{tabular}{|c|c|c|c|c|c|}
\hline & \multirow{2}{*}{$\begin{array}{l}\text { Indicator title } \\
\text { Percentage of patients: }\end{array}$} & \multicolumn{2}{|c|}{$\begin{array}{l}\text { Homework } \\
\text { score }\end{array}$} & \multirow[b]{2}{*}{$\begin{array}{l}\text { Decision after } \\
\text { homework }\end{array}$} & \multirow[b]{2}{*}{$\begin{array}{l}\text { Decision after } \\
\text { discussion }\end{array}$} \\
\hline & & $\begin{array}{l}\text { Median } \\
\text { score }\end{array}$ & $\begin{array}{l}\text { Most } \\
\text { prior }\end{array}$ & & \\
\hline I & With a score of 3 or less on a scale of 0 to 10 (average over 3 days) for pain & $6^{b}$ & 4 & Discard & \\
\hline 2 & Who were most of the time or always treated for pain & $7^{\mathrm{b}}$ & 4 & Discard & \\
\hline 3 & Who, after treatment, experienced significant improvement in pain & 9 & 6 & Select & Minimal set \\
\hline 4 & With a score of 3 or less on a scale of 0 to 10 (average over 3 days) for anxiety & $7^{\mathrm{b}}$ & 2 & Discard & \\
\hline 5 & Who were most of the time or always guided for anxiety & $6^{b}$ & 4 & Discard & \\
\hline 6 & Who, after treatment, experienced significant improvement in anxiety & $7^{\mathrm{b}}$ & 5 & Discard & \\
\hline 7 & $\begin{array}{l}\text { Who indicated that the caregivers were most of the time or always attentive to their } \\
\text { personal situation and needs }\end{array}$ & 8 & 4 & Discuss & Discard \\
\hline 8 & Who indicated that the caregivers regularly assessed how they were feeling & 8 & 5 & Discuss & Minimal set \\
\hline 9 & $\begin{array}{l}\text { Who were most of the times or always offered counselling when they were not feeling } \\
\text { well or feeling less well }\end{array}$ & 8 & 3 & Discard & \\
\hline 10 & With a score of 5 or more on a scale of 0 to 10 for psychological well-being & $6^{\mathrm{b}}$ & 4 & Discard & \\
\hline 11 & $\begin{array}{l}\text { Who indicated that the caregivers regularly talked to them about spirituality and } \\
\text { religion in an understanding way }\end{array}$ & $7^{b}$ & 2 & Discard & \\
\hline 12 & With a score of 5 or more on a scale of 0 to 10 for spiritual well-being & $6^{\mathrm{b}}$ & 2 & Discard & \\
\hline 13 & With a score of 5 or more on a scale of 0 to 10 for social well-being & $6^{b}$ & 0 & Discard & \\
\hline 14 & With a score of 5 or more on a scale of 0 to 10 for quality of life & 8 & 8 & Select & Minimal set \\
\hline 15 & $\begin{array}{l}\text { Who in dicated that they could most of the time or always be alone and talk to someone } \\
\text { undisturbed if wanted }\end{array}$ & $7^{b}$ & 2 & Discard & \\
\hline 16 & $\begin{array}{l}\text { Who in dicated that the caregivers most of the times or always respected their personal } \\
\text { wishes and that they could most of the time or always plan their day and decide about } \\
\text { the care provided }\end{array}$ & 9 & 8 & Select & Minimal set \\
\hline 17 & Who indicated that most or all of their caregivers respected their philosophy of life & $7^{b}$ & 2 & Discard & \\
\hline 18 & Who indicated that a priest or spiritual counsellor was available & $5^{b}$ & 0 & Discard & \\
\hline 19 & Who received the right amount of information about their diagnosis & 8 & 6 & Discuss & Minimal set \\
\hline 20 & Who received the right amount of information about their prognosis & 8 & 3 & Discard & \\
\hline 21 & Who received the right amount of information about the course of the disease & 8 & 5 & Discuss & Minimal set \\
\hline 22 & $\begin{array}{l}\text { Who received the right amount of information on the advantages and disadvantages of } \\
\text { treatments }\end{array}$ & 8 & 2 & Discard & \\
\hline 23 & Who received the right amount of information on palliative care options & 8 & 5 & Discuss & Minimal set \\
\hline 24 & $\begin{array}{l}\text { Who indicated that they most of the time or always received clear and comprehensible } \\
\text { and never or sometimes contradictory information }\end{array}$ & 8 & 4 & Discuss & Minimal set \\
\hline 25 & Who indicated that they discussed their wishes about care objectives with a physician & 8 & 3 & Discard & \\
\hline 26 & Who are not receiving treatments they do not want & 8 & 3 & Discard & \\
\hline 27 & Who are not receiving drugs they do not want & $6^{\mathrm{b}}$ & 0 & Discard & \\
\hline 28 & $\begin{array}{l}\text { Who were most of the time or always able to have some privacy with their family carers } \\
\text { if wanted }\end{array}$ & 6 & 2 & Discard & \\
\hline 29 & $\begin{array}{l}\text { Who believed that their caregivers were sufficiently informed of their medical care } \\
\text { history to be able to provide the best possible care }\end{array}$ & $6^{b}$ & 0 & Discard & \\
\hline 30 & $\begin{array}{l}\text { Who most of the time or always felt they were given continuous care by their various } \\
\text { caregivers }\end{array}$ & 8 & 1 & Discard & \\
\hline 31 & Who mostly or entirely knew who to talk to about their care & 7 & 2 & Discard & \\
\hline
\end{tabular}

Median score: on a scale from I to 9. Most prior: number of times found most prior by the experts.

'The experts did not reach consensus on these indicators in the first scoring round (home assignment). 
Leemans, K., Deliens, L., Block, L. van den, Stichele, R. Vander, Francke, A.L., Cohen, J. Systematic quality monitoring for specialized palliative care services: development of a minimal set of wuality indicators for palliative care study (QPAC). American Journal of Hospice \& Palliative Medicine: 2017, 34(6), 532-546

Table 4. Scores and Decisions Per Round of the Indicators Included in the Caregivers Questionnaire. ${ }^{2}$

\begin{tabular}{|c|c|c|c|c|c|}
\hline & \multirow{2}{*}{$\begin{array}{l}\text { Indicator title } \\
\text { Percentage of patients: }\end{array}$} & \multicolumn{2}{|c|}{$\begin{array}{l}\text { Homework } \\
\text { score }\end{array}$} & \multirow[b]{2}{*}{$\begin{array}{l}\text { Decision after } \\
\text { homework }\end{array}$} & \multirow[b]{2}{*}{$\begin{array}{l}\text { Decision after } \\
\text { discussion }\end{array}$} \\
\hline & & $\begin{array}{l}\text { Median } \\
\text { Score }\end{array}$ & $\begin{array}{l}\text { Most } \\
\text { prior }\end{array}$ & & \\
\hline I & Who were subjected to a general symptom assessment on a validated scale & 8 & 7 & Select & Minimal set \\
\hline 2 & Who were subjected to a pain assessment, with or without pain scale & 8 & 9 & Select & Minimal set \\
\hline 3 & Who were subjected to a delirium assessment, with or without delirium scale & 7 & 4 & Discard & \\
\hline 4 & Treated for delirium & 6 & 2 & Discard & \\
\hline 5 & For whom the delirium improved substantially or completely after the treatment & 6 & I & Discard & \\
\hline 6 & $\begin{array}{l}\text { Whose shortness of breath was relieved within } 48 \text { hours after admission or starting } \\
\text { palliative care }\end{array}$ & 8 & 7 & Select & Minimal set \\
\hline 7 & Who were subjected to an anxiety assessment, with or without anxiety scale & 8 & 6 & Discuss & Discard \\
\hline 8 & Who were asked how they felt about end of life decisions and euthanasia & $8^{\mathrm{b}}$ & 8 & Discuss & Minimal set \\
\hline 9 & $\begin{array}{l}\text { About whom a conversation about their care preferences took place between the } \\
\text { caregivers and family carers in the first week after admission or start of pal liative care }\end{array}$ & 8 & 6 & Discuss & Minimal set \\
\hline 10 & $\begin{array}{l}\text { Whom multidisciplinary consultations took place at least once a week about their care } \\
\text { objectives }\end{array}$ & 8 & 5 & Discuss & Minimal set \\
\hline II & $\begin{array}{l}\text { Whose family physician was regularly or always involved in these multidisciplinary } \\
\text { consultations }\end{array}$ & 6 & 4 & Discard & \\
\hline 12 & Whose wishes on resuscitation (DNR code) are known to the caregivers & $7^{\mathrm{b}}$ & 6 & Discard & \\
\hline 13 & $\begin{array}{l}\text { Whose family physician, home nurse, and physiotherapist (when available) were } \\
\text { involved in the care }\end{array}$ & 7 & 4 & Discard & \\
\hline 14 & $\begin{array}{l}\text { Whose caregivers were given information about care and treatment prior to admission } \\
\text { or starting palliative care }\end{array}$ & 8 & 4 & Discuss & Discard \\
\hline 15 & $\begin{array}{l}\text { Whose caregivers were given a summary of the patient's medical records during the } \\
\text { admission or after starting palliative care }\end{array}$ & 8 & 5 & Discuss & Discard \\
\hline 16 & $\begin{array}{l}\text { Whose caregivers were given the care objectives and resuscitation status during or } \\
\text { after admission or starting palliative care }\end{array}$ & 8 & 5 & Discuss & Minimal set \\
\hline 17 & $\begin{array}{l}\text { For whom the prognosis, psychosocial symptoms, functional status, symptom burden } \\
\text { and documentation about care wishes were entered in the file within } 48 \text { hours after } \\
\text { admission or starting palliative care }\end{array}$ & 8 & 7 & Select & Minimal set \\
\hline
\end{tabular}

Median score: on a scale from I to 9. Most prior: number of times found most prior by the experts.

bThe experts did not reach consensus on these indicators in the first scoring round (home assignment). 
Leemans, K., Deliens, L., Block, L. van den, Stichele, R. Vander, Francke, A.L., Cohen, J. Systematic quality monitoring for specialized palliative care services: development of a minimal set of wuality indicators for palliative care study (QPAC). American Journal of Hospice \& Palliative Medicine: 2017, 34(6), 532-546

Table 5. Scores and Decision Per Round of the Indicators Included in the Questionnaire for Family Carers. ${ }^{2}$

\begin{tabular}{|c|c|c|c|c|c|}
\hline & \multirow{2}{*}{$\begin{array}{l}\text { Indicator title } \\
\text { Percentage of: }\end{array}$} & \multicolumn{2}{|c|}{$\begin{array}{l}\text { Homework } \\
\text { score }\end{array}$} & \multirow[b]{2}{*}{$\begin{array}{l}\text { Decision after } \\
\text { homework }\end{array}$} & \multirow[b]{2}{*}{$\begin{array}{l}\text { Decision after } \\
\text { discussion }\end{array}$} \\
\hline & & $\begin{array}{l}\text { Median } \\
\text { score }\end{array}$ & $\begin{array}{l}\text { Most } \\
\text { prior }\end{array}$ & & \\
\hline 1 & Patients for whom the delirium improved sufficiently after the treatment & 7 & 0 & Discard & \\
\hline 2 & $\begin{array}{l}\text { Family carers who indicated that caregivers were most of the time or always attentive to } \\
\text { their anxiety and despondency }\end{array}$ & 8 & 2 & Discard & \\
\hline 3 & $\begin{array}{l}\text { Family carers who indicated that the caregivers regularly talked to them about what it } \\
\text { was meant to them to care for their ill next of kin }\end{array}$ & 8 & 7 & Select & Minimal set \\
\hline 4 & Family carers who indicated that the caregivers regularly asked how they were feeling & 8 & 10 & Select & Minimal set \\
\hline 5 & $\begin{array}{l}\text { Family carers who were most of the time or always offered counselling when they were } \\
\text { not feeling well or feeling less well }\end{array}$ & 8 & 3 & Discard & \\
\hline 6 & $\begin{array}{l}\text { Family carers who indicated that the caregivers regularly talked to them about } \\
\text { spirituality and religion in an understanding way }\end{array}$ & 6 & 0 & Discard & \\
\hline 7 & $\begin{array}{l}\text { Family carers who indicated that most or all of the caregivers respected their } \\
\text { philosophy of life }\end{array}$ & 7 & 1 & Discard & \\
\hline 8 & $\begin{array}{l}\text { Patients who got a positive response to (all) their request(s) for a treatment or an end- } \\
\text { of-life decision }\end{array}$ & 9 & 11 & Select & Minimal set \\
\hline 9 & $\begin{array}{l}\text { Patients who received the right amount of information about the treatment or end-of- } \\
\text { life decision they requested }\end{array}$ & 8 & 3 & Discard & \\
\hline 10 & $\begin{array}{l}\text { Patients who were involved in the final treatment or end-of-life decision (after a request } \\
\text { of the patient) }\end{array}$ & 8 & 2 & Discard & \\
\hline 11 & $\begin{array}{l}\text { Patients (or family carers in case the patient lacked capacity) who were sufficiently } \\
\text { informed when a treatment or end-of-life decision was taken }\end{array}$ & 8 & 4 & Discuss & Discard \\
\hline 12 & $\begin{array}{l}\text { Patients (or family carers where the patient lacked capacity) who were involved in the } \\
\text { treatment or end-of-life decision (without a request of the patient) }\end{array}$ & 8 & 3 & Discard & \\
\hline 13 & $\begin{array}{l}\text { Family carers who received sufficient information about palliative lump sum and } \\
\text { palliative leave }\end{array}$ & 8 & 2 & Discard & \\
\hline 14 & $\begin{array}{l}\text { Family carers who received the right amount of information about the patient's } \\
\text { condition and treatments }\end{array}$ & 8 & 9 & Select & Minimal set \\
\hline 15 & $\begin{array}{l}\text { Family carers who received the right amount of information about the patient's } \\
\text { approaching death }\end{array}$ & 9 & 7 & Select & Minimal set \\
\hline 16 & $\begin{array}{l}\text { Family carers who received clear and comprehensible and noncontradictory } \\
\text { information about the patient's approaching death }\end{array}$ & 8 & 4 & Discuss & Discard \\
\hline 17 & $\begin{array}{l}\text { Patients for whom starting or terminating administration of artificial fluids and/or } \\
\text { nutrition was discussed with family carers }\end{array}$ & $7^{b}$ & 4 & Discard & \\
\hline 18 & Patients whose authorized representative was involved when the patient lost capacity & 8 & 5 & Discuss & Discard \\
\hline 19 & Patients who scored 5 or more on a scale of 0 to 10 for the quality of death & 8 & 5 & Discuss & Minimal set \\
\hline 20 & $\begin{array}{l}\text { Family carers who were most of the time or always able to have some privacy with the } \\
\text { patient if wanted }\end{array}$ & $7^{\mathrm{b}}$ & 0 & Discard & \\
\hline 21 & $\begin{array}{l}\text { Family carers who felt they had adequate support after the patient's death (indusive } \\
\text { evaluation meeting) and were informed of the possibilities of after-care. }\end{array}$ & 8 & 5 & Discuss & Minimal set \\
\hline 22 & $\begin{array}{l}\text { Family carers who were given as much assistance and training as necessary for practical } \\
\text { issues and had someone available for help with these issues }\end{array}$ & 8 & 6 & Discuss & Discard \\
\hline 23 & Family carers who were given as much assistance as necessary with the care process & 8 & 4 & Discuss & Minimal set \\
\hline
\end{tabular}

2Median score: on a scale from I to 9. Most prior: number of times found most prior by the experts.

'The experts did not reach consensus on these indicators in the first scoring round (home assignment). 
Leemans, K., Deliens, L., Block, L. van den, Stichele, R. Vander, Francke, A.L., Cohen, J. Systematic quality monitoring for specialized palliative care services: development of a minimal set of wuality indicators for palliative care study (QPAC). American Journal of Hospice \& Palliative Medicine: 2017, 34(6), 532-546

Table 6. Scores and Decisions Per Round for the Indicators Included in the Questionnaire for Physicians. ${ }^{a}$

\begin{tabular}{|c|c|c|c|c|}
\hline \multicolumn{2}{|r|}{ Indicator title } & \multirow{2}{*}{$\frac{\text { Homework score }}{\text { Median score }}$} & \multirow{2}{*}{$\begin{array}{l}\text { Decision after } \\
\text { homework }\end{array}$} & \multirow{2}{*}{$\begin{array}{l}\text { Decision after } \\
\text { discussion }\end{array}$} \\
\hline & Percentage of patients: & & & \\
\hline I & Whose symptom burden was mostly or completely under control in the final week of life & 9 & Select & Minimal set \\
\hline 2 & With whom the physician discussed the care objectives & 9 & Select & Minimal set \\
\hline 3 & Who were not started on artificial fluids and/or nutrition in the last month before death & $7^{\mathrm{b}}$ & Discuss & Discard \\
\hline 4 & Whose palliative care started at least 2 weeks before death & 8 & Select & Minimal set \\
\hline 5 & $\begin{array}{l}\text { Who were not started on a new course of chemotherapy after admission or start } \\
\text { of palliative care }\end{array}$ & $7^{b}$ & Discuss & Minimal set \\
\hline 6 & $\begin{array}{l}\text { Admitted more than once to the emergency room since admission or start of } \\
\text { palliative care }\end{array}$ & 8 & Select & Minimal set \\
\hline 7 & Admitted to the intensive care unit since admission or start of palliative care & 7 & Select & Minimal set \\
\hline 8 & $\begin{array}{l}\text { Who scored } 5 \text { or more on a scale of } 0 \text { to } 10 \text { for the quality of death (according to family } \\
\text { carers and physicians) }\end{array}$ & 9 & Select & Minimal set \\
\hline 9 & $\begin{array}{l}\text { Who were in touch with their family physician on a weekly basis in the last } 3 \text { months } \\
\text { before death (personally or by telephone) }\end{array}$ & 7 & Select & Minimal set \\
\hline
\end{tabular}

${ }^{a}$ Median score: on a scale from I to 9 . Most prior: number of times found most prior by the experts.

${ }^{\mathrm{b}}$ The experts did not reach consensus on these indicators in the first scoring round (home assignment). 